\title{
Indigenous Knowledge among Artisans Can Promote Scientific Literacy for Education in the Thailand 4.0 Era: Perspectives of Thai Science Scholars
}

\author{
Warissara Kraijitmate, Virapong Saeng-xuto, \\ and Kreetha Kaewkhong*
}

Faculty of Education, Chiang Mai University, Chiang Mai 50200, Thailand

*Corresponding author. E-mail:kreetha.ka@cmu.ac.th

https://doi.org/10.12982/CMUJASR.2017.0009

\begin{abstract}
Thailand development policy focuses on developing people of all ages and building up their Thainess to create a strong society with high morality. The learning process and curriculum are relevant to the locality. This paper explores the meaning of scientific literacy and the guidelines for teaching by using indigenous knowledge among artisans to promote scientific literacy drive for education in the Thailand 4.0 era. The data were collected through focus group discussions using five questions about scientific literacy. The participants were eight Thai science scholars, selected by purposive sampling, who have experience in science education. The ideas of each Thai scholar are summarized by the researcher and are confirmed by the individuals. This study found that the meaning of scientific literacy is the individual's knowledge, understanding, and ability to use scientific knowledge, scientific processes, and scientific mindset to analyze and evaluate information, construct scientific concepts, as well as apply knowledge to solving problems in his or her daily life. The findings can be used to design and develop science curriculum. Science educators should collect and analyze information, creating science curriculum and textbooks integrated with indigenous knowledge that artisans could use to create products or inventions with modern science and technology to add value to the existing ones and transfer knowledge to other areas. This would result the student's life and career skills development, leading to the commercial value-adding. This could move Thailand from a middle-income country to a high-income country.
\end{abstract}

Keywords: Indigenous knowledge, Artisan, Scientific literacy, Education in the Thailand 4.0 era 


\section{INTRODUCTION}

Education is an important mechanism for national and human capital development, as it enables people to enjoy the benefits of analytical thinking, morality, ethics, and citizenship to accompany literacy, as well underpinning career and economic skills to maintain a happy life in society. This will help increase the country's competitiveness and reduce social inequalities in the long run (Working group on reform preparation for returning happiness to the people in the nation, 2016). The government has a development policy for 'Thailand $4.0^{\prime}$ ', which is a vision for national economic development. Thailand 4.0 is bringing about a transformation in society towards the value-based economy; from more for less to less for more. The economy is driven by innovation for security, prosperity and sustainability. This policy is aimed at stepping out of the middle-income trap to become a high income country in which social change is driven by scientific research, technology and innovation ('Speech by Thai prime minister', 2017). While science and technology are the key factors driving the global change that affects every country, a culture of science and technology will emerge to impact the lives of people (Murcia, 2006; Coll and Taylor, 2009). In a speech at the National Science and Technology Fair 2011, HRH Princess Maha Chakri Sirindhorn, stated that:

"Nowadays, it is generally recognized that science and technology are a powerful mechanism. They can change the world and people's way of life. The change could either be constructive or destructive. Therefore, it is essential to help construct a broader understanding of science and technology for the youth and citizens to make the right judgment how science and technology should be used for sustaining the world and society." (Pongsutarn, 2011) 
The speech apparently implies that citizens should understand scientific knowledge and concepts, and be awarene of their impact on society. That means Thai citizens should be scientifically literate people.

Science education is an important element in the strategy for developing scientifically literate people (Shwartz et al., 2006; Lima et al., 2010; Rusilowati et al., 2016). Scholars and organizations related to science education similarly define the meaning of scientific literacy as an ability to use knowledge and scientific skills for describing natural phenomena, finding the answers and applying them to everyday life and being aware of science's impact on human, society, and environment (The Institute for the Promotion of Teaching Science and Technology, 2002; Norris \& Philips, 2003; Miller, 2006; Royal institute, 2012; Organization for Economic Co-operation and Development, 2013; Fives et al., 2014). Scientific literacy is a universal necessity for contributing to social inclusiveness and equality, as well as strengthening the critical capacity of a society (González-Weil et al., 2014). Scientific literacy refers to what the general community ought to know about science in order to have the competence and disposition to use science to meet the personal and social demands of life at home, at work and in the community (Murcia, 2009). People can use scientific concepts to identify problems, while raising scientific questions can enable them to construct new knowledge by themselves, explain the phenomena, and draw evidence-based conclusions. These encompass an awareness of the impact of science and technology on citizens and the environment (OECD, 2013).

Recently, education in Thailand has focused on two dimensions: 1) Thai-based development such as Thai values, morality, and arts and culture that serve as the firm roots of life, and, 2) universal-based development that prepare for competition and, at the same tie, living together with others like sprawling flowers for a stable and sustainable existence in the world (Watanachai, 2016). The development policy taken by the Prime Minister and the Cabinet aims to develop people of all ages, based on integrating education, religion, art, culture, pride in history and Thai culture to drive for a strong and quality society that has a sense of being Thai. The policy is also to develop people of all ages by promoting lifelong learning to gain new knowledge and skills to pursue a career in accordance with future employment prospects. The learning process and curriculum are linked to the social landscape by integrating knowledge and virtues together to facilitate student develop- 
ment of knowledge and skills for pursuing learning, solving problems, listening, and opinion providing, having ethics, and obtaining good citizenship. The emphasis is on cooperation between those involved inside and outside of the school, conserving, restoring, and disseminating cultural heritage, Thai and dialects and indigenous knowledge. This includes a variety of Thai arts and cultural practices for learning, having pride in history and Thai language and culture. These in turn lead to good national, regional, and international relationships and generate increased economic value to the country (Chan-ocha, 2014). Education should promote the identity of each locality by emphasizing participation from all sectors of society. It is important that this should be managed by incorporating morality and ethics (Working group on reform preparation for returning happiness to the people in the nation, 2016).

Indigenous knowledge includes knowledge of morality. This is a way of teaching people to respect one another's sacred values, and nature depending on nature without any break (Thai Junior Encyclopedia Project by Royal Command of H.M. the King, 1996). Indigenous knowledge is unique to a given culture or society. It is the information base that facilitates communication and decision-making in a society. Indigenous knowledge is also a systematic body of knowledge acquired by a local people through the accumulation of experiences of informal experiments, and intimate understanding of the environment in a given culture (Warren \& Rajasekaran, 1993). Artisans receive knowledge through transmission of indigenous knowledge from generation to generation (Thompson, 1999) and construct new knowledge through their activities and practices (Charoenying, 2005). People in the past had many scientific processes skills for learning, including principles and scientific knowledge in various fields of creation (Ngamkeeree et al., 2006).

This study presents the perspectives of Thai science scholars on the meaning of science. How can indigenous knowledge among artisans promote scientific literacy? Thailand development policy focuses on the developing the country in the Thailand 4.0 era to step out of the middle-income trap and into high-income country status, but the challenge is how to integrate scientific literacy from artisans into the science classroom. The reason we choose studying only the perspective of science scholars is because their works had a large impact on the promotion of scientific literacy in Thailand before the Thailand 4.0 era, particulary in the aspects of scientific communication, scientific research and the development of science curriculum for science teachers in Thailand. They are all pioneers who play an important role in driving Thailand through scientific literacy. 


\section{METHODOLOGY}

This study is qualitative research drawing on focus group discussions to collect data. Focus group discussion, a useful research tool, gives the researcher insights and details in their area of study. Group interaction enables the researcher to gain in-depth data through collecting ideas and exchange among participants (Kitzinger \& Barbour, 1999; Hennink, 2007; Liamputtong, 2011; Krueger \& Casey, 2015). Focus group discussion is a highly flexible research tool which can be applied to any issue. It can ensure accuracy, reliability and diversity of information, providing results quickly (Kroll et al., 2007). The data collection for this study was conducted in December 2016. A total of eight participants recruited by purposive sampling comprised 2 focus groups. The focus group discussions were conducted in two locations - Bangkok and Chiang Mai. Participants gathered together to discuss specific issues facilitated by a moderator in a setting where participants felt comfortable to engage in a dynamic discussion (Kitzinger \& Barbour 1999; Hennink, 2007; Liamputtong, 2011; Krueger \& Casey, 2015). Discussion of the questions was finished in between 60 and 90 minutes (Greenbaum, 1998; Krueger, 1998; Liamputtong, 2011). Participants comprised a homogenous sample (Liamputtong, 2011; Krueger \& Casey, 2015) of science scholars. The socio-demographic characteristics of participants are shown in Table 1. 


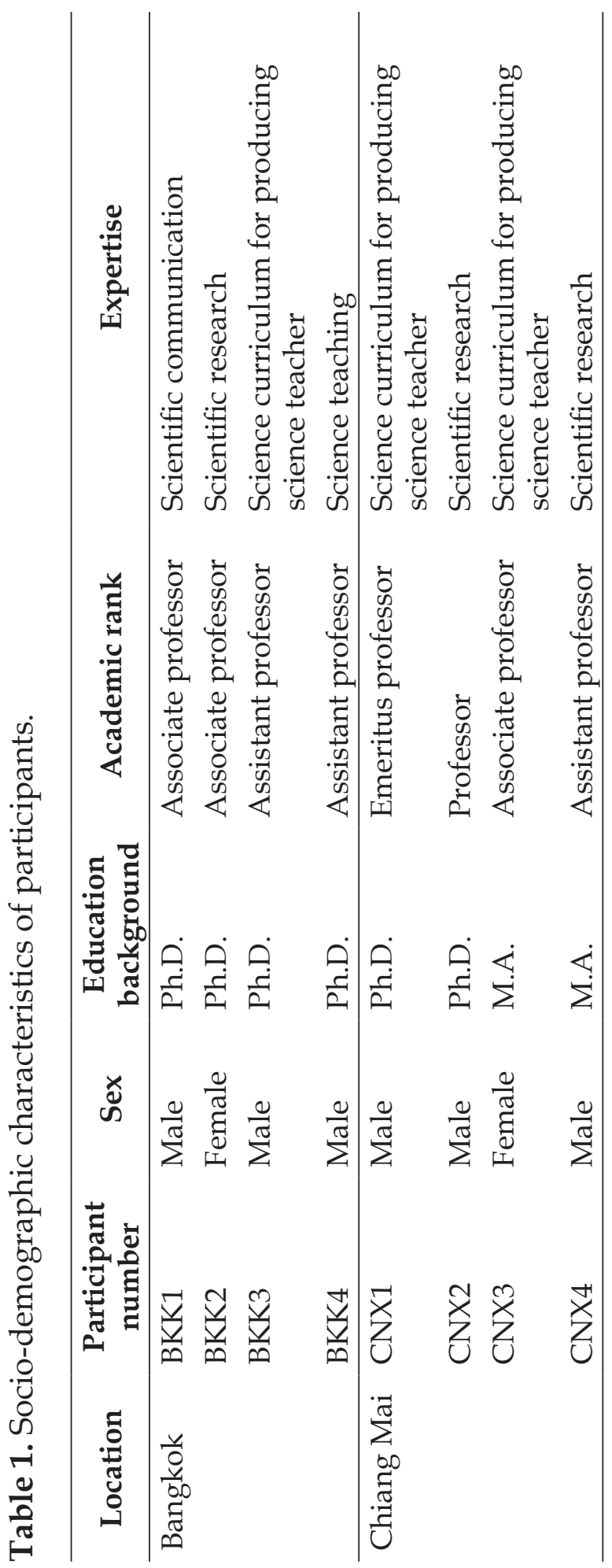


The focus group discussion was started by the moderator, who had prepared a set of focus group discussion guidelines. The moderator provided an introduction the discussion, providing an overview of the study's purpose, a summary of the definition of scientific literacy and education in the Thailand 4.0 era of innovation). Next, participants were encouraged to share their opinions (Liamputtong, 2011; Aggarwal et al., 2016). The discussion was divided into three parts: 1) the meaning of scientific literacy, 2) how indigenous knowledge among artisans can promote scientific literacy, and 3) how to integrate scientific literacy from artisans into the science classroom. All participants had a chance to offer their ideas, but if an individual did not talk, the moderator would stimulate conversation with the question "What do you have to say?". Before the end of the discussion, the moderator asked all participants to give a final comment. The dialogue group reflected on the answers and gave the participants another chance to comment. The questions presented in focus group discussion are shown in Table 2.

Information in all group discussions were recorded using three recorders: Sony (ICD-UX543F), Sony (ICD-UX533F) and iPhone 6, which were placed at the front and the end of the table. Recordings were transcribed verbatim (Schapira et al., 2014; Krueger \& Casey, 2015; Aggarwal etal., 2016; Beckman \&Hagquist, 2016; Cunningham etal., 2016). and sent back to all participants to confirm the authenticity before being used for data analysis. 
Table 2. Focus group discussion guide.

\begin{tabular}{|c|c|}
\hline Discussion topic & Question \\
\hline \multicolumn{2}{|l|}{$\begin{array}{l}\text { Welcome and introduction } \\
\text { (15 min) }\end{array}$} \\
\hline \multicolumn{2}{|l|}{ Question (45 min) } \\
\hline Defining scientific literacy & $\begin{array}{l}\text { In your opinion, what is the meaning of } \\
\text { scientific literacy? }\end{array}$ \\
\hline $\begin{array}{l}\text { Promoting scientific } \\
\text { literacy from artisans }\end{array}$ & $\begin{array}{l}\text { As you are a science scholar who has } \\
\text { much experiences, how can indigenous } \\
\text { knowledge among artisans can promote } \\
\text { scientific literacy? }\end{array}$ \\
\hline $\begin{array}{l}\text { Artisan Scientific Literacy } \\
\text { for Education in the } \\
\text { Thailand } 4.0 \text { era }\end{array}$ & $\begin{array}{l}\text { Thailand development policy focuses on } \\
\text { developing the country to drive } \\
\text { Thailand } 4.0 \text { out of the middle-income } \\
\text { trap to a be high-income country. How } \\
\text { can scientific literacy from artisans be } \\
\text { integrated into the science classroom? }\end{array}$ \\
\hline Reflecting back (15 min) & $\begin{array}{l}\text { If you have an opportunity to give more } \\
\text { information, what information would } \\
\text { you give? }\end{array}$ \\
\hline $\begin{array}{l}\text { Wrap up and final } \\
\text { comments (15 min) }\end{array}$ & $\begin{array}{l}\text { Is there anything that we should talk } \\
\text { about missed out in today's discussion? }\end{array}$ \\
\hline
\end{tabular}

\section{RESULTS}

All participants shared ideas based on their opinions and experiences in the three areas described above. The findings are summarized below.

- Definition of Scientific Literacy.

All participants discussed the meaning of scientific literacy. Key points that were raised in thes discussions include:

“... Scientific literacy is not just reading and writing but it means being able to perceive, analyze and evaluate the information..." (BKK1) 
“...Scientific literacy is not only knowledge but also scientific processing skills..." (BKK4)

“...Scientific literacy means learning to understand and apply it - understanding various theoretical rules and the nature of science, knowing science processing skills, what is science and what is technology?..." (CNX3)

“...Scientific literacy should be communicated, and pay attention to science for observation and taking action..." (CNX4)

“...A scientifically literate person should be composed of three elements: 1) understand the nature of science, 2) create scientific knowledge by themself, and, 3) have life skills in science and technology..." (BKK3)

“... Citizens should be scientifically literate people. They should have a knowledge of science and technology that is sufficient for communicating and applying it. They should have an awareness of ideas to find the truth by using scientific knowledge and and application. They should also believe in science and take action. They must pay attention to science.." (CNX1)

From the perspectives of Thai science scholars, scientific literacy is knowledge, understanding, and the ability to use scientific knowledge, scientific processes and scientific mindset to analyze and evaluate information, create scientific concepts as well as apply knowledge to problem-solving in their daily lives. Scientifically literate people will follow the following process: 1) use knowledge and understanding of science, analysis, and evaluation; 2) create scientific knowledge through scientific processes; 3) apply scientific knowledge to use in daily life and communication; 4) have a scientific mindset and practice as a guideline; 5) always pursue scientific knowledge and follow up; and 6) understand that science has a role in society. The elements of meaning related to scientific literacy are synthesized in Table 3 as components of scientific literacy. 
Table 3. The synthesis of Scientific Literacy's components.

\begin{tabular}{|c|c|c|c|c|c|c|c|c|}
\hline \multirow{2}{*}{$\begin{array}{l}\text { The components of } \\
\text { Scientific Literacy }\end{array}$} & \multicolumn{8}{|c|}{ Participants } \\
\hline & $\begin{array}{c}\text { BKK } \\
1 \\
\end{array}$ & $\begin{array}{c}\text { BKK } \\
2 \\
\end{array}$ & $\begin{array}{c}\text { BKK } \\
3 \\
\end{array}$ & $\begin{array}{c}\text { BKK } \\
4 \\
\end{array}$ & $\begin{array}{c}\text { CNX } \\
1 \\
\end{array}$ & $\begin{array}{c}\text { CNX } \\
2 \\
\end{array}$ & $\begin{array}{c}\text { CNX } \\
3 \\
\end{array}$ & $\begin{array}{c}\text { CNX } \\
4 \\
\end{array}$ \\
\hline $\begin{array}{l}\text { 1. Science content } \\
\text { knowledge }\end{array}$ & $\checkmark$ & $\checkmark$ & $\checkmark$ & $\checkmark$ & $\checkmark$ & $\checkmark$ & $\checkmark$ & $\checkmark$ \\
\hline 2. Scientific processes & $\checkmark$ & $\checkmark$ & $\checkmark$ & $\checkmark$ & $\checkmark$ & $\checkmark$ & $\checkmark$ & $\checkmark$ \\
\hline 3. Scientific mindset & $\checkmark$ & & $\checkmark$ & $\checkmark$ & $\checkmark$ & & $\checkmark$ & \\
\hline $\begin{array}{l}\text { 4.Apply knowledge } \\
\text { for use in daily life }\end{array}$ & $\checkmark$ & $\checkmark$ & $\checkmark$ & & $\checkmark$ & & $\checkmark$ & \\
\hline
\end{tabular}

Table 3 shows that in the participants' view, the most important elements of scientific literacy science are content knowledge and scientific processes. Scientific mindset and application of knowledge for use in daily life given less importance.

- Promoting scientific literacy from artisans.

All participants discussed how indigenous knowledge among artisans could promote scientific literacy. Key comments are highlighted here.

“... We actually have all science knowledge which our grandparents used in the past, but but we have never collected it. Instead, we have felt the need to take knowledge that has been generated by foreign educators. If we have our own science textbooks, we should draw on learning and science from artisans or through indigenous knowledge. These use real samples in a laboratory instead of simply taking foreign knowledge. We need to analyze artisan's materials to formulate ideas on how to construct our own curriculum and teach science based on these... " (CNX3)

“... In schools, the teacher could teach science by showing connections to indigenous knowledge and then let the student know how to apply that knowledge. Artisans who have a lot of experience know how to develop themselves and obtaining new scientific knowledge that is useful for the villagers. When the teacher works in science class, they should not just let the time run out, should provide the students with examples so they can get new knowledge. The teachers realise that that they use both scientific process and mindset in their searching for new knowledge, but they did not know how to pass it on.." (CNX1) 
“.. We need to create our own textbooks using lessons because some things are far away and we cannot see them. But the children are living their everyday lives and we can do many things to bring the subject matter closer to students' lives. If there is something that needs to be brought up, it must be linked to an inquiry into what the original man did. How do we deal with science today? ..." (CNX2)

“...Villagers burn charcoal. They do not know if the burning is done or not. They just know that if they remove the husk, the soil is too thick. They have observations, which are actually science..." (BKK3)

“... What does one think or study? How did it get into real life? This is another motivation..." (BKK4)

From the discussion, it could be concluded that indigenous knowledge is knowledge that is close and practical to everyday life in each locality. It is easy to understand and use for individuals. The relevant agencies should collect and analyze this knowledge. Textbooks and science curriculum can be created based on the knowledge of the artisans living in northern parts of Thailand, who specialize in works of creation related to indigenous knowledge. To teach science, teachers should synthesize and connect indigenous knowledge to create products or inventions relevant to culture and local context. This is scientific process of thinking and problem solving in education. The teacher must ask questions to stimulate leaning of real science that consists of content, scientific process and scientific mind to conduct and to find the new knowledge by themselves.

\section{0 era.}

- Artisan Scientific Literacy driving Education in the Thailand

All participants discussed how to integrate scientific literacy from artisans into the science classroom to drive education in the Thailand 4.0 era? Comments are highlighted below.

“... I'm interested in scientific process. If we have strong grasp of scientific process, we can analyze and synthesize. You should know what the things are, but this should be analyzed and subjected to scientific criticism. The data should connect with one another. Understanding scientific process leads us to analysis and synthesis, and this brings critical thinking..." (CNX2) 
“... He really has a good thing called wisdom, which he has created himself. This might be food food or handicrafts produced in the community. Although he is skilled, he might not be aware of the fact that the creation of the product was actually science in practice..." (BKK2)

“... We teach only scientific facts, so the students do not know how to apply science in their everyday life. The teaching should include analysis and synthesis, and help students come to love their own wisdom..." (CNX3)

"... The children should analyze the value of what they learn by themselves, while the the teacher must emphasize the value of learning. The must decode tacit indigenous knowledge to reveal explicit knowledge for use in creating their lessons..." (CNX4)

“...The students should construct knowledge by themselves with scientific thinking and empirical experiments. It will be useful when they can apply these in their everyday life. I think of this type of science as life skills..." (BKK3)

"... Education in Thailand should analyze the context of the students and schools, as well as science content..." (BKK4)

From the discussion, we can see that teaching science based on the experience of the artisans will promote the education of innovative learners in the era of Thailand 4.0. The creation of textbooks or science curriculum by analyzing and decoding knowledge from artisans is relevant for the process of learning and creating knowledge that would help students understand the history, roots and values of what they learn. Importantly, this also includes how how this understanding can be applied in everyday life. The scientific process enables students to analyze and synthesize products and inventions as innovation with high social value. Knowledge of issues such as 1) adherence to the principle of cause and effect, 2) thinking and acting in a systematic way, and 3) use of factual information can be an important area of reliancefor students. 


\section{DISCUSSION}

Thailand 4.0 is an economic model that the Thai government has developed to lead the country out of the middle-income trap and step up to be a high income country. It is bringing about a transformation towards a value-based economy. The concept of "more for less to less for more" is driven by scientific research, technology and innovation for security, prosperity and sustainability. The results of this research reveal that teaching science based on the experience of artisans who specialize in creative works related to indigenous knowledge will promote scientific literacy and the education of learners in the Thailand 4.0 era of innovation. We agree completely with the perspective of the eight Thai science scholars involved in this study.. In our opinion, one way to help students close the gap between school science, applications of science and technology and their critical evaluation can be brought about by designing science lessons to include societal issues and discussions involving science and technology (Holbrook, 1998; Ratcliffe, 1998; Albe, 2008; Marks \& Eilks, 2009).

The Organization of Economic Co-operation and Development (2013) stated that scientific literacy referred to an individual having found four components comprised of 1) scientific knowledge and use of that knowledge to identify questions, acquire new knowledge, explain scientific phenomena and draw evidence-based conclusions about science-related issues, 2) understanding of the characteristic features of science as a form of human knowledge and inquiry, 3) awareness of how science and technology shape people's material, intellectual and cultural environments, and, 4) willingness to engage in science-related issues with the ideas of science, as a reflective citizen. Furthermore, Office of Science and Technology Washington D.C. (2016) has introduced a guideline for the introduction of scientific literacy into educational development. We can summarize from the group discussions that scientific literacy is a knowledge, understanding, and ability to use science content knowledge, scientific processes and the scientific mindset to analyze and evaluate information, create scientifics concepts as well as apply knowledge to problem-solving in their daily lives, as has been explored in previous research (Holbrook \& Rannikmae, 2009). It is noteworthy that Thai science scholars agree that science content knowledge and scientific processes are important components of scientific literacy. Considering these findings, we agree that the curriculum and teaching of science should connect concepts, principles, content, and processes that are universal but still consistent with real life. They also provide to students with different 
aptitudes and interests by using a variety of teaching strategies. All learners are encouraged to develop their learning abilities, thinking processes, and search for knowledge. At the same time, they should develop appropriate moral and ethical attitudes and approaches to science, technology and environment, as suggested by previous research (Colucci-Gray et. al ,2006; Webb, 2009). In addition, it is important to support the use of local learning resources in conjunction with classroom learning. Indigenous knowledge is understood as practical, personal, and contextual. This unit of knowledge cannot be detached from the individual, his community, or the environment in either physical or spiritual senses (Abah et al., 2015). In the teaching of science, we agree that teachers should synthesize and connect indigenous knowledge to create new products or inventions relevant to local culture and social context. The creation of textbooks or science curriculum by analyzing and decoding knowledge from the artisans, including the processes of learning and creating knowledge, will help students understand the values of what they learn. Moreover, they gain understanding of how to apply them to their everyday life. Before indigenous knowledge can be included in the curriculum, however, researchers need become more knowledgeable in not only the content of indigenous knowledge, but how indigenous people teach it to their children and the processes by which indigenous people think as well. Understanding the epistemological underpinnings of different indigenous knowledge systems remains a daunting task. Science education researchers can at least try to identify commonalities and differences between the knowledge systems of indigenous non-Western science and Western science. An understanding of epistemological differences will provide important markers for how to proceed with integrating indigenous knowledge into a science curriculum (Hewson, 2012). Although school science curriculum is developed based on modern Western science that presents science using canonical knowledge, techniques, and Eurocentric worldviews (Mijung, 2016). We fully agree that indigenous knowledge can be integrated into the school curriculum for improving learning outcome, in was similar to what was communicated by the eight Thai scholars in this study, as well as perspectives presented in other research (Colucci-Gray et. al ,2006; Webb, P., 2009; Kaino, 2013). In many cases, teaching science has promoted academic science and this has created difficulty for students in finding connections between the science they are taught in school and the problems they face in their daily lives (Sarkar \& Corrigan, 2014). Moreover, the lack of connection between the content 
taught and the students' context is revealed in classroom teaching. The lack of connection between what students study and what they live is a blockage in their learning. Using resources to presenting the student with problems rooted in real-life situations will help real understanding (Gonzalez-Weil et al., 2014). Indigenous knowledge could help advance scientific understanding (UNESCO, 2009). Moreover, the knowledge acquired through conventional science, which is usually closed and formal, can be analyzed through indigenous knowledge systems, which are open and informal. Conventional science formulates principles and theories that describe nature, whereas indigenous knowledge system evolved values, beliefs, customs and rituals based on an understanding of nature and the universe. While conventional science relies on conceptualization, empirical experiment and interpretations to generate and share knowledge, indigenous knowledge on the other hand focuses on experience and practice (Dhewa, 2011). Indigenous knowledge should be integrated with modern science and technology, and continues to innovate to add value to existing products or inventions, to be able to transfer and use in other areas. This will result lifelong skills and career skills for students so they can further expand and innovate commercial products in the future.

In further work to continue this line of inquiry, we will analyze and decode indigenous knowledge in our local area of northernThailand to construct a local science curriculum. The science curriculum will be used by local science teachers who are volunteers in their own science class room, and the effects of this science learning experience will be studied.

\section{ACKNOWLEDGEMENT}

The research reported in this paper was undertaken as part of Warissara Kraijitmate's doctoral study. The authors would like to acknowledge the contributions of the participants who were willing to attend the focus group discussion and share their critical perspectives, which were invaluable. 


\section{REFERENCES}

Abah, J., Mashebe, P. \& Denuga, D.D. (2015). Prospect of integration African indigenous knowledge systems into the teaching of sciences in Africa. American Journal of Educational Research, 3(6), 668-673. https:// doi.org/10.12691/education-3-6-1

Aggarwal, N.K., Cedeno, K., Guarnaccia, P., Kleinman, A. \& LewisFernandez, R. (2016). The meanings of cultural competence in mental health: An exploratory focus group study with patients, clinicians, and administrators. SpringerPlus, 5(384): 1-13. https:/ / doi.org/10.1186/ s40064-016-2037-4

Albe, V. (2008). When scientific knowledge, daily life experience, epistemological and social considerations intersect: Students' argumentation in group discussions on a socioscientific issue. Research in Science Education, 38(1), 67-90. https://doi.org/10. 1007/s11165-007-9040-2

Beckman, L. \& Hagquist, C. (2016). Views of bullying and antibullying working style among school nurse and school social workers in Sweden. Journal of School Violence, 15, 438-459. https:/ / doi.org/10.1080/15388220.2015.1084234

Chan-ocha, P. (2014). Government policy statement. Retrieved from http:/ / www.most.go.th/main/index.php/about-us/policy-most/ 2558/3947.html

Charoenying, P. (2005). Thai indigenous knowledge treasure of Siam. Bangkok: Matichon.

Colucci-Gray, L., Camino, E., Barbiero, G. \& Gray, D. (2006). From scientific literacy to sustainability literacy: An ecological framework for education, Science Education, 90(2), 227-252. https://doi.org/10.1002/sce.20109

Coll, R.K. \& Taylor, N. (2009). Exploring international perspectives of scientific literacy: An overview of the special issue. International Journal of Environment and Science Education, 4(3), 197-200.

Cunningham, C.E., Rimas, H., Mielko, S., Mapp, C., Cunningham, L., Buchanan, D., ... Marcus, M. (2016). What limits the effectiveness of antibullying programs? A thematic analysis of the perspective of teachers. Journal of School Violence, 15, 460-482. https://doi.org/10.1080/15388220.2015.1095100

Dhewa, C. (2011). Modern science needs traditional knowledge. Retrieved from http://www.scidev.net/global/indigenous/ opinion/modern-science-needs-traditional-knowledge-1.html 
Fives, H., Huebner, W., Birnbaum, S.A., \& Nicolich, M. (2014). Developing a measure of scientific literacy for middle school students. Science Education,4(98):549-580.https:/ / doi.org/10.1002/sce.21115 González-Weil, C., Merino-Rubilar, C., Ahumada, G., Arenas, A., Salinas, V., \& Bravo, P. (2014). The local territory as a resource for learning science: A proposal for the design of teaching-learning sequences in science education. Procedia - Social and Behavioral Sciences, 116: 4199-4204. https://doi.org/10.1016/j.sbspro.2014. 01.916

Greenbaum, T.L. (1998). The handbook for focus group research ( $2^{\text {nd }}$ ed.). Thousand Oaks, CA: Sage Publications.

Hennink, M.M. (2007). International focus group research: A handbook for the health and social science. Cambridge: Cambridge University Press. Hewson, G.M. (2012). Traditional healers' views on their indigenous knowledge and the science curriculum. African Journal of Research in Mathematics, Science and Technology Education, 16(3): 317-332. https:/ / doi.org/10.1080/10288457.2012.10740748

Holbrook, J. (1998). Operationalising scientific and technological literacy - a new approach to science teaching. Science Education International, 9(2), 13-18.

Holbrook, J., \& Rannikmae, M. (2009). The meaning of scientific literacy. International Journal of Environmental and Science Education, 4(3), 275-288.

Kaino, L.M. (2013). Traditional knowledge in curricula designs: Embracing indigenous mathematics in classroom instruction. Studies of Tribes and Tribals, 11(1): 83-88. https:/ / doi.org/10.1080/ 0972639X.2013.11886669

Kitzinger, J., \& Barbour, R.S. (1999). Introduction: the challenge and promise of focus groups. In R. S. Barbour and J. Kitzinger (Eds.), Developing Focus Group Research. (p. 120). Thousand Oaks, CA: SagePublications.

Kroll, T., Barbour, R., \& Harris, J. (2007). Using focus groups in disability research. Qualitative Health Research, 17(5), 690-698. https:/ / doi.org/10.1177/1049732307301488

Krueger, R.A. (1998). Moderation focus groups. Thousand Oaks, CA: Sage Publications.

Krueger, R.A., \& Casey, M.A. (2015). Focus groups: A practical guide for applied research ( $5^{\text {th }}$ ed.) Thousand Oaks, CA: Sage Publications. Liamputtong, P. (2011). Focus group methodology. Thousand Oaks, CA: Sage Publications. 
Lima, A., Vasconcelos, C., Félix, N., Barros, J., \& Mendonça, A. (2010). Field trip activity in an ancient gold mine: Scientific literacy in informal education. Public Understanding of Science, 19(3), 322-344. https://doi.org/10.1177/0963662509104725

Marks, R., \& Eilks, I. (2009). Promoting scientific literacy using a sociocritical and problem-oriented approach to chemistry teaching: concept, examples, experiences. International Journal of Environmental and Science Education, 4(3), 231-245.

Mijung, K. (2016). Indigenous knowledge in Canadian science curricula: Cases from Western Canada. Cultural Studies of Science Education, 12, 605-613. https:// doi.org/10.1007/s11422-016-9759-z

Miller, J.D. (2006). Civic scientific literacy in Europe and the United States. A paper presented to the annual meeting of the World Association for Public Opinion Research. Montreal, Canada.

Murcia, K. (2006). Scientific literacy for sustainability. School of Education Murdoch University Perth, Western Australia.

Murcia, K. (2009). Science in the news: An evaluation of students' scientific literacy. Teaching Science, 55(3), 40-45. https:/ / doi.org/ 10.1080/87567555.2014.916650

Ngamkeeree, S., U-Panno, P., Seang-Xuto, V., Tongthaworn, R., \& Thipkasorn, S. (2006). The collection and analysis of scientific knowledge from the local toy in Chiang Mai and Chiangrai provinces. Chiang Mai: Faculty of Education Chiang Mai University.

Norris, S., \& Phillips, L. (2003). How literacy in its fundamental sense is central to scientific literacy. Science Education, 87,224-240. Office of Science and Technology Washington D.C. (2016). Scientific Literacy. Retrieved from http://ost.thaiembdc.org/2016/ $\mathrm{w}$-content/ uploads / 2016/05/รายงานการรู้เรื่องวิทยาศาสตร์.pdf

Organization for Economic Co-operation and Development. (2013). PISA 2012 Assessment and analytical framework: Mathematics, reading, science, problem solving and financial literacy: OECD publishing. Retrieved from http://dx.doi.org/10.1787/9789264190511-en Pongsutarn, P. (2011). HRH Princess Maha Chakri Sirindhorn, the Princess of Thai dynasty, presiding over the opening ceremony of the National Science and Technology fair 2011. Retrieved from http:/ / www.most. go.th/main/th/34-news/news-gov/2380-2011-08-10-04-14-54

Ratcliffe, M. (1998). Discussing socioscientific issues in science lessons: Pupils' action and the teacher's role. School Science Review, 79(288), 55-59. 
Royal Institute. (2012). Dictionary of education terminology the royal institute. Bangkok: Aroonkarnpim.

Rusilowati, A., Kurniawati, L., Nugroho, E.S. \& Widiyatmoko, A. (2016). Developing an instrument of scientific literacy assessment on the cycle theme. International Journal of Environmental and Science Education,11(12), 5718-5727.

Sarkar, M., \& Corrigan, D. (2014). Promotion of scientific literacy: Bangladeshi teachers' perspectives and practices. Research in Science and Technological Education, 32(2), 162-181.

Schapira, M.M., Imbert, D., Oh, E., Byhoff, E., \& Shea, J.A. (2014). Public Engagement with scientific evidence in health: A qualitative study among primary-care patients in an urban population. Public Understanding of Science, 15, 1-15. https:/ / doi. org/10.1177/0963662514560489

Shwartz, Y., Ben-Zvi, R., \& Hofsyein, A. (2006). The use of scientific literacy taxonomy for assessing the development of chemical literacy among high-school students. Chemical Education Research and Practice, 7(4): 203-225. https:// doi.org/10.1039/B6RP90011A

Speech by Thai Prime Minister Prayuth Chan-ocha at Opening Conference and Keynote Speech. (2017). Retrieved from http:/ / www.nesdb.go.th/download/document/Year end/2017/Speech_Gov.pdf

Thai Junior Encyclopedia Project by Royal Command of H.M. the King. (1996). Local Wisdom. In Thai junior encyclopedia project by royal Command of H.M. the King $(19,245-263)$. (2nd Ed). Bangkok: Rungroung Printing.

The Institute for the Promotion of Teaching Science and Technology. (2002). Handbook of Science Teaching. Bangkok: Kurusapa Printing Ladphrao.

Thompson, B.I. (1999). The role of artisan technology and indigenous knowledge transfer in the survival of a classic cultural landscape: The marais salants of Guerande, Loire-Atlantique, France. Journal of Historical Geography, 2(25): 216-234. UNESCO. (2009). Synergies between scientific and indigenous knowledge. Retrieved from http://www.unesco.org/csi/LINKS/ posters2009/ENG\%20LR/synergies.pdf

Warren, D.M., \& Rajasekaran, B. (1993). Putting local knowledge to good use. International Agricultural Development, 13(4): 8-10. 
Watanachai, K. (2016). Education system. Chiangmai University Council Newsletter, 1(1): 4.

Webb, P. (2009). Towards an integrated learning strategies approach to promoting scientific literacy in the south African context. International Journal of Environmental and Science Education, 4(3), 313-334.

Working group on reform preparation for returning happiness to the people in the nation. (2016). Framework for Thailand's reform of education. Office of The Permanent Secretary for Defence. 